\title{
Níveis de ácido fólico em dietas contendo ácido fórmico para leitões de 21 a 48 dias de idade ${ }^{1}$
}

\author{
Anderson Corassa ${ }^{2}$, Darci Clementino Lopes ${ }^{3}$, José Dagoberto Ostermann ${ }^{4}$, Alexandre Mendes \\ Sanfelice ${ }^{4}$, Alexandre de Oliveira Teixeira ${ }^{2}$, Gérson Fausto da Silva ${ }^{2}$, Sérgio de Miranda Pena ${ }^{2}$ \\ ${ }^{1}$ Parte da tese do primeiro autor apresentada ao Programa de Pós-graduação em Zootecnia da UFV. Projeto de pesquisa parcialmente \\ financiado pela METACHEM Ind. e Com. LTDA. \\ 2 Pós-graduação em Zootecnia - UFV. \\ ${ }^{3}$ Departamento de Zootecnia - UFV. \\ ${ }^{4}$ Médico Veterinário e Químico.
}

RESUMO - Foi conduzido um experimento com o objetivo de avaliar níveis de ácido fólico em dietas suplementadas com ácido fórmico para leitões de 21 a 48 dias de idade. Foram utilizados 160 leitões de 5,67 $\pm 0,90 \mathrm{~kg}$, em um delineamento experimental de blocos casualizados, com cinco tratamentos, oito repetições e quatro animais por repetição. Formularamse duas dietas basais, pré-inicial I (21 a 35 dias) e pré-inicial II (36 a 48 dias), balanceadas para atender às exigências nutricionais dos animais e adicionadas de ácido fórmico em 0,24 e $0,20 \%$, respectivamente. Os tratamentos consistiram de cinco níveis de ácido fólico: $0 ; 0,30 ; 0,60 ; 0,90$ e $1,20 \mathrm{mg} / \mathrm{kg}$ de ração. O desempenho dos leitões foi avaliado nos períodos de 21 a 35, 36 a 48 e 21 a 48 dias de idade. No 49o dia, os animais submetidos a jejum e oito leitões por tratamento foram destinados à coleta de sangue, para confecção de hemograma e quantificação de folato. Não houve efeito dos níveis de ácido fólico sobre o consumo médio diário de ração (CMDR) em nenhum dos períodos analisados. A adição de ácido fólico melhorou o ganho de peso médio diário de forma quadrática, enquanto a conversão alimentar foi influenciada pelos níveis de ácido fólico apenas no período de 21 a 35 dias. Os valores de hematócrito, hemoglobina e hemácias aumentaram de forma linear conforme os níveis de ácido fólico. Os valores de folato sérico diminuíram com o aumento de ácido fólico na dieta. Dietas com ácido fórmico para leitões de 21 a 48 dias de idade devem ser suplementadas com 0,64 mg de ácido fólico por $\mathrm{kg}$ de ração.

Palavras-chave: acidificante, desempenho, folato sérico, hemácias, hematócrito, hemograma

\section{Levels of folic acid in diets containing formic acid for piglets from 21 to 48 days old}

ABSTRACT - A trial was conduced with to evaluate the levels of folic acid in diets supplemented with formic acid for piglets from 21 to 48 days old. 160 crossbred piglets were used with initial average weight of $5.67 \pm 0,90 \mathrm{~kg}$ in a completely randomized experimental block design, with five treatments, eight replications of four animals each. Two basal diets with increasing formic acid levels $(0.24$ and $0.20 \%$ ) were formulated (pre-starter $\mathrm{I}=$ from 21 to 35 days old and pre-starter II = from 36 to 48 days old) to meet the animal nutritional requirements. The treatments consisted of five dietary levels of folic acid: $0,0.30,0.60,0.90$, and $1.20 \mathrm{mg} / \mathrm{kg}$. Piglets performance was evaluated at three periods: from 21 to 35 days, from 36 to 48 days and from 21 to 48 days. At $49^{\text {th }}$ day, animals were fasted and blood samples of eight piglets from each treatment were collected for folate quantification. No effect of dietary levels of folic acid on daily average feed intake was observed in the analyzed periods. Increasing folic acid levels increased quadractlyaverage daily weight gain and affected feed:gain ratio only from 21 to 35 days. Hematocrit, hemoglobin and red blood cell values increased linearly with increasing folic acid levels. Serum folate values decreased as dietary folic acid levels increased. Diets with formic acid for piglets from 21 to 48 days old should be supplemented with $0.64 \mathrm{mg}$ of folic acid per $\mathrm{kg}$ of diet.

Key Words: acidifier, serum folate, hematocrit, hemogram, hemoglobin, performance

\section{Introdução}

O desmame e os dias subseqüentes têm constituído, do ponto de vista nutricional, um período crítico no desenvolvimento de leitões. Para minimizar seus efeitos negativos, os nutricionistas têm utilizado aditivos, como os acidificantes, entre os quais destaca-se o ácido fórmico, um ácido orgânico utilizado com os objetivos de reduzir o pH do trato digestivo, aumentar a ação da pepsina, reduzir a taxa de esvaziamento do estômago, aumentar a digestão de peptídeos e reduzir a proliferação de patógenos (Lima, 1999). 
Estudos têm evidenciado melhoria no ganho de peso e na conversão alimentar de leitões alimentados com dietas suplementadas com ácido fórmico (Eckel et al., 1992; Partanen, 2001; Tsiloyiannis et al., 2001), sais de cálcio (Kirchgebner \& Roth, 1987a; 1990), sódio (Kirchgebner \& Roth, 1987b), potássio(Paulicks et al., 1996; 2000; Partanen, 2001)e "blends" (Mroz, 2002; Silva et al., 2002; Teixeira et al., 2003).

Entretanto, a adição de quantidades excessivas de formiatos na dieta pode causar distúrbios no perfil ácido-base de suínos, promovendo a acidose metabólica e resultando em diminuição do consumo e do crescimento (Giesting et al., 1991; Eckel et al.,1992; Eidelsburger et al., 1992; Grassmann et al., 1992). A acumulação do formiato no sangue pode ocasionar ainda toxemia ocular e até morte (Makar et al., 1990; Teply, 1991).

O ácido fórmico é absorvido e transportado ao fígado, onde é metabolizado a dióxido de carbono em um processo que requer tetrahidrofolato. Os suínos, por sua vez, têm níveis extremamente baixos de tetrahidrofolato hepático eníveis muito baixos da enzima-chave 10-formil tetrahidrofolato desidrogenase na via do folato (Partanen, 2001). Assim, sua habilidade para metabolizar formiato pode ser limitada (Johlin et al., 1987; Makar et al., 1990).

Apesar dos sintomas tóxicos de seu excesso, o formiato é um metabólico natural, um membro do "pool" de um carbono-dependente do folato, dentro de uma relação linear entre a taxa de oxidação do formiato em $\mathrm{CO}_{2}$ e o tetrahidrofolato hepático (Polonen et al., 1997). A deficiência de ácido fólico pode resultar em baixos níveis de tetrahidrofolato, forma coenzimática ativa que atua na degradação do formiato (McDowell, 2000), além de ocasionar problemas como anemia megaloblástica e leucopenia, caracterizada pela redução no número de células brancas (Polonen et al., 1997; McDowell, 2000).

Estudos têm demonstrado que a suplementação dietética de ácido fólico em suínos e outras espécies pode aumentar as reservas hepáticas de folato (Letendre et al., 1991; Lindemann et al., 1993) e a taxa de oxidação de formiato (Polonen et al., 1997; 2002).

O ácido fólico, uma vitamina hidrossolúvel absorvida pela célula intestinal e reduzida a tetrahidrofolato, é liberado na corrente sangüínea e está envolvido nas reações de transferência do grupo metil, como a síntese de metionina e serina (Ewan, 1996). O papel metabólico do ácido fólico nos tecidos mamários envolve a transferência de unidades simples de carbono, como metil, formil, formiato ou hidroximetil, e as formas co-enzimáticas ativas da vitamina são os derivados do tetrahidrofolato (Dove \& Cook, 2001). O aumento nas necessidades de ácido fólico pode ser conseqüência de dietas deficientes ou do aumento na sua demanda, que pode ser aumentada com o uso de ácido fórmico.
Verifica-se, portanto, a necessidade de se avaliar níveis de ácido fólico em dietas suplementadas com acidificantes à base de ácido fórmico para leitões recém- desmamados na fase de 21 a 48 dias de idade.

\section{Material e Métodos}

Conduziu-se um experimento no Setor de Suinocultura do Departamento de Zootecnia da Universidade Federal de Viçosa utilizando-se 160 leitões ( 80 machos e 80 fêmeas) desmamados aos 21,47 $\pm 2,05$ dias de idade, com peso médio inicial de 5,67 $\pm 0,90 \mathrm{~kg}$. Os tratamentos consistiram de cinco níveis de ácido fólico: 0; 0,30; 0,60;0,90 e 1,20 mg/kg de ração. Foi utilizado um delineamento experimental de blocos casualizados, com dois blocos (leves e pesados), dois sexos, oito repetições e quatro animais de mesmo sexo por repetição, totalizando 32 animais por tratamento. Os critérios para formação de blocos foram sexo e peso dos animais, resultando em duas repetições de cada sexo por bloco.

Os animais foram alojados em galpão de creche com piso ripado suspenso, em baias de 2,00 x 1,20 m, equipadas com comedouros semi-automáticos e bebedouros tipo chupeta. Água e ração foram fornecidas ad libitum e a ventilação e a temperatura do ambiente foram controladas por abertura e fechamento das básculas do galpão e por meio de lâmpadas de aquecimento.

Foram utilizadas duas dietas basais, uma para o período de 21 a 35 dias de idade (pré-inicial I) e outra para o período de 36 a 48 dias de idade (pré-inicial II), formuladas de acordo com as recomendações de Rostagno et al. (2000). A composição centesimal e nutricional destas dietas podem ser visualizadas nas Tabelas 1 e 2 , respectivamente.

À exceção do ácido fólico, todas as dietas apresentaram a mesma composição (Tabela 1). As rações foram formuladas considerando o valor tamponante ( $B$-value) (Vergdut, 2002) dos ingredientes, de forma a ajustar o $\mathrm{pH}$ final para não interferir na atuação do acidificante. O acidificante com $20 \%$ de ácido fórmico foi utilizado nos níveis de 1,2\% (fase préinicial I) e 1,0\% (fase pré-inicial II), conforme recomendação do fabricante. A suplementação de ácido fólico foi feita gradativamente à pré-mistura vitamínica e consecutivamente às rações experimentais, desconsiderando o seu valor nos ingredientes.

As variáveis avaliadas foram ganho de peso médio diário (GPMD), consumo médio diário de ração (CMDR) e conversão alimentar (CA). As rações, as sobras e os animais (aos 21, 35 e 48 dias deidade) foram pesados para determinação do consumo.

No 49o dia, após jejum de seis horas, quatro machos e quatro fêmeas com peso mais próximo da média de cada 
Tabela 1 - Composição centesimal das rações experimentais para os períodos pré-inicial I e II

Table 1 - Ingredient composition of the experimental pre-starter I and I/ diets

\begin{tabular}{|c|c|c|}
\hline \multirow[t]{2}{*}{$\begin{array}{l}\text { Ingrediente }(\%) \\
\text { Ingredient }\end{array}$} & \multicolumn{2}{|c|}{$\begin{array}{c}\text { Dieta basal } \\
\text { Basal diet }\end{array}$} \\
\hline & $\begin{array}{l}\text { Pré-inicial I } \\
\text { Pré-initial I }\end{array}$ & $\begin{array}{c}\text { Pré-inicial II } \\
\text { Pré-initial II }\end{array}$ \\
\hline Milho & 31,10 & 49,22 \\
\hline $\begin{array}{l}\text { Soja farelo } \\
\text { Soybean meal }\end{array}$ & 22,80 & 23,40 \\
\hline $\begin{array}{l}\text { Milho pré-cozido } \\
\text { Pre-gelatinized corn }\end{array}$ & 15,00 & 5,00 \\
\hline $\begin{array}{l}\text { Soro de leite em pó } \\
\text { Milk whey powered }\end{array}$ & 13,9 & 5,50 \\
\hline $\begin{array}{l}\text { Soja micronizada } \\
\text { Micronized soybean }\end{array}$ & 5,00 & 5,00 \\
\hline $\begin{array}{l}\text { Farinha de peixe }(55 \%) \\
\text { Fish meal }\end{array}$ & 4,00 & 4,00 \\
\hline $\begin{array}{l}\text { Açúcar } \\
\text { Sugar }\end{array}$ & 3,00 & 3,00 \\
\hline $\begin{array}{l}\text { Amido de milho } \\
\text { Corn starch }\end{array}$ & 0,06 & 0,100 \\
\hline $\begin{array}{l}\text { Óleo de soja } \\
\text { Soybean oil }\end{array}$ & 1,16 & 0,982 \\
\hline $\begin{array}{l}\text { Fosfato mono-bicálcico } \\
\text { Mono-dicalcium phosphate }\end{array}$ & 0,570 & 0,836 \\
\hline $\begin{array}{l}\text { Acidificante } \\
\text { Acidifier }^{1}\end{array}$ & 1,200 & 1,000 \\
\hline $\begin{array}{l}\text { Óxido de zinco } \\
\text { Zinc oxide }\end{array}$ & 0,300 & - \\
\hline $\begin{array}{l}\text { Sal } \\
\text { Salt }\end{array}$ & 0,366 & 0,436 \\
\hline $\begin{array}{l}\mathrm{L} \text {-lisina } \mathrm{HCl} \\
\text { L-lysine } \mathrm{HCl}\end{array}$ & 0,638 & 0,670 \\
\hline L-treonina & 0,328 & 0,318 \\
\hline $\begin{array}{l}\text { L-threonine } \\
\text { DL-metionina }\end{array}$ & 0,309 & 0,274 \\
\hline $\begin{array}{l}\text { DL-methionine } \\
\text { L- triptofano }\end{array}$ & 0,059 & 0,058 \\
\hline $\begin{array}{l}\text { L-thryptophan } \\
\text { Mistura vitamínica }{ }^{2}\end{array}$ & 0,100 & 0,100 \\
\hline $\begin{array}{l}\text { Vitamin mix } \\
\text { Mistura mineral }\end{array}$ & 0,100 & 0,100 \\
\hline $\begin{array}{l}\text { Mineral mix } \\
\text { BHT } \\
\text { Total }\end{array}$ & $\begin{array}{l}0,010 \\
100,00\end{array}$ & $\begin{array}{l}0,010 \\
100,00\end{array}$ \\
\hline
\end{tabular}

${ }^{1}$ Acidificante com $20 \%$ de ácido fórmico.

2 Conteúdo/kg de suplemento vitamínico: vitamina A - 6.000.000 UI; vitamina D3 - 1.500.000 Ul; vitamina E - $1.500 \mathrm{UI}$; vitamina K3 - $1.500 \mathrm{mg}$; vitamina B1 - $1.350 \mathrm{mg}$; vitamina B2 $-4.000 \mathrm{mg}$; vitamina B6 $-2.000 \mathrm{mg}$; vitamina B12-20.000 mg; ácido nicotínico - $20.000 \mathrm{mg}$; ácido pantotênico $-9.350 \mathrm{mg}$; biotina - $80 \mathrm{mg}$; selênio - $300 \mathrm{mg}$; veículo $-1.000 \mathrm{~g}$.

3 Conteúdo/kg de ração: Fe - 100 mg; Cu - 10 mg; Co - 1 mg; Mn - 40 mg; $\mathrm{Zn}-100 \mathrm{mg}$; I - 1,5 mg.

unidade experimental de cada tratamento foram submetidos à coleta de sangue para confecção de hemograma e dosagem de folato sérico. Foram coletadas duas amostras de $5 \mathrm{~mL}$ de sangue de cada animal por punção venosa do sinus orbital utilizando-se seringa e agulha esterilizadas e secas. As amostras destinadas ao hemograma foram depositadas em frasco esterilizado e seco com anticoagulante
Tabela 2 - Composição nutricional das rações experimentais para os períodos pré-inicial I e II

Table 2 - Nutritional composition of experimental pré-starter I and II diets

\begin{tabular}{|c|c|c|}
\hline \multirow[t]{2}{*}{$\begin{array}{l}\text { Nutriente } \\
\text { Nutrient }\end{array}$} & \multicolumn{2}{|c|}{$\begin{array}{c}\text { Dieta basal } \\
\text { Basal diet }\end{array}$} \\
\hline & $\begin{array}{l}\text { Pré-inicial I } \\
\text { Pré-initial I }\end{array}$ & $\begin{array}{c}\text { Pré-inicial II } \\
\text { Pré-initial II }\end{array}$ \\
\hline $\begin{array}{l}\text { Energia digestível }(\mathrm{kcal} / \mathrm{kg}) \\
\text { Digestible energy }\end{array}$ & 3,500 & 3,500 \\
\hline $\begin{array}{l}\text { Gordura }(\%) \\
\text { Fat } \\
\text { Proteína bruta }(\%)\end{array}$ & 4,101 & 4,450 \\
\hline $\begin{array}{l}\text { Crude protein } \\
\text { Lisina digestível (\%) }\end{array}$ & $\begin{array}{l}21,00 \\
1,240\end{array}$ & $\begin{array}{l}21,00 \\
1,240\end{array}$ \\
\hline Digestible lysine & & \\
\hline $\begin{array}{l}\text { Met }+ \text { Cist digestível }(\%) \\
\text { Digestible methionine }+ \text { cystine }\end{array}$ & 0,720 & 0,720 \\
\hline $\begin{array}{l}\text { Metionina digestível (\%) } \\
\text { Digestible methionine }\end{array}$ & 0,486 & 0,470 \\
\hline $\begin{array}{l}\text { Treonina digestível (\%) } \\
\text { Digestible threonine }\end{array}$ & 0,800 & 0,800 \\
\hline $\begin{array}{l}\text { Triptofano digestível (\%) } \\
\text { Digestible thryptophan }\end{array}$ & 0,220 & 0,220 \\
\hline $\begin{array}{l}\text { Cálcio }(\%) \\
\text { Calcium }\end{array}$ & 0,769 & 0,770 \\
\hline $\begin{array}{l}\text { Cálcio digestível (\%) } \\
\text { Digestible calcium }\end{array}$ & 0,634 & 0,574 \\
\hline $\begin{array}{l}\text { Fósforo disponível (\%) } \\
\text { Available phosphorus }\end{array}$ & 0,450 & 0,450 \\
\hline Sódio $(\%)$ & 0,320 & 0,280 \\
\hline $\begin{array}{l}\text { Sodium } \\
\text { Lactose }(\%)\end{array}$ & 10,00 & 4,00 \\
\hline Lactose & & \\
\hline $\mathrm{pH}$ & 5,36 & 5,35 \\
\hline B-value & 13,21 & 11,08 \\
\hline $\begin{array}{l}\text { Ácido fórmico (\%) } \\
\text { Formic acid }\end{array}$ & 0,24 & 0,20 \\
\hline
\end{tabular}

(EDTA, $1 \mathrm{mg} / \mathrm{mL}$ ) segundo protocolo descrito por Pardini (2003a). A dosagem de folato sérico foi realizada após a coagulação do sangue e centrifugação das amostras, retirando-se alíquotas de 1,0 mL de soro. Para determinação quantitativa de folato no soro, utilizou-se o kit Folato ADVIA Centaur (Cat. no 124974), adaptado à técnica de quimioluminescência direta, que quantifica o folato preso às proteínas de ligação, validado pelo procedimento descrito por Tremblay et al. (1986). As amostras foram identificadas, acondicionadas em caixa de isopor com gelo, enviadas ao laboratório e submetidas a processo automatizado com leitura realizada pelo aparelho SYSMIEX K1000, efetuando-se contagem de hematócrito por microcentrifugagem específica. Na análise hematológica, foram quantificados: hematócrito, hemoglobina, hemácias, volume corpuscular médio (VCM), hemoglobina corpuscular média (HCM), concentração de hemoglobina corpuscular média (CHCM) e leucócitos.

O modelo estatístico utilizado para os dados de desempenho, hemograma e folato sérico foi: $\mathrm{Yijk}=\mu+\mathrm{Ni}+\mathrm{Bj}+\mathrm{Sk}$ + eijk, em que: Yijk = observação relativa ao nível de ácido 
fólico i, no bloco j, para o sexo $\mathrm{k} ; \mu=$ média geral, $\mathrm{Ni}=$ efeito do nível de ácido fólico $\mathrm{i}$, em que $\mathrm{i}=0,00$ a 1,$20 ; \mathrm{Bj}=$ efeito do bloco $\mathrm{j}$, em que $\mathrm{j}=1$ a $2 ; \mathrm{Sk}=$ efeito do sexo $\mathrm{k}$, em que $\mathrm{k}=1$ a 2; e eijk = erro experimental associado a cada observação.

Os dados de desempenho, hemograma e folato sérico foram submetidos à análise de regressão utilizando-se o programa SAEG(UFV, 1999).

\section{Resultados e Discussão}

Os valores de peso corporal, consumo médio diário de ração (CMDR), ganho de peso médio diário (GPMD) e conversão alimentar (CA) e suas equações de regressão, ajustadas conforme o nível do ácido fólico nas dietas, estão dispostos na Tabela 3.

Não houve efeito dos tratamentos sobre o CMDR em nenhum dos períodos analisados, contrariando resultado compilado por Dove \& Cook (2001).

Para os três períodos avaliados, observou-se efeito quadrático $(\mathrm{P}<0,05)$ dos tratamentos sobre o GPMD. Nos períodos de 21 a 35, 36 a 48 e 21 a 48 dias, os aumentos máximos estimados para GPMD, de acordo com as equações dispostas na Tabela 3 e na Figura 1, foram de 0,65; 0,63 e $0,64 \mathrm{mg} / \mathrm{kg}$ de ração, respectivamente. Melhora no ganho de peso médio diário de suínos, em decorrência da adição de ácido fólico, também foi observada por Lindemann \& Kornegay (1986), com a utilização de $0,5 \mathrm{mg} / \mathrm{kg}$ de ração para leitões desmamados aos 28 dias. Polonen et al. (1997), ao administrarem níveis crescentes de ácido fólico na dieta de visões (Mustela vision), constataram melhora no GPMD e efeito quadrático nas taxas de oxidação do ácido fórmico em $\mathrm{CO}_{2}$. Houve efeito dos tratamentos sobre a conversão alimentar apenas no primeiro período avaliado, com melhora quadrática $(\mathrm{P}<0,05)$ até o nível estimado de $0,57 \mathrm{mg} / \mathrm{kg}$ de ração, de acordo com a equação constante na Tabela 3 . Paulicks et al. (2000), avaliando a adição de diformiato de Potássio em dietas para leitões de 21 a 63 dias de idade, obtiveram melhora significativa no ganho de peso e na conversão alimentar em comparação à dieta controle, com $0,3 \mathrm{mg} / \mathrm{kg}$ de ácido fólico. Polonen et al. (2002) investigaram a interação ácido fólico $\times$ ácido fórmico em raposas azuis (Alopex lagopus) e não observaram efeito no crescimento dos animais que receberam suplementação com ácido fólico. Entretanto, os níveis crescentes diminuíram de forma linear à meia-vida do ácido fórmico no organismo.

A partir do desenho experimental deste estudo e da natureza do ácido fólico, era esperado desempenho mínimo, seguido de um acréscimo e um platô, de acordo com os níveis crescentes de suplementação. No entanto, isso não ocorreu, o que não pode ser atribuído a efeito tóxico, pois, segundo McDowell (1989), o nível tóxico do ácido fólico em suínos tem sido estimado em 400 mg ou mais. Uma hipótese para explicar esse comportamento pode ser o menor status de folato sérico encontrado nos animais alimentados com os maiores níveis de ácido fólico $(0,90$ e 1,20 mg/kg). O menor aporte de folato pode ter causado acúmulo de formiato, em decorrência da limitada oxidação, visto que a taxa de oxidação do formiato depende do nível de folato no organismo (Partanen \& Mroz, 1999), gerando acidose (Makar et al., 1990), limitando o consumo de ração e, conseqüentemente, o ganho de peso (Giesting et al., 1991; Eckel et al., 1992a; Eidelsburger et al., 1992e; Grassmann et al., 1992).

Os melhores níveis de ácido fólico encontrados neste trabalho, em torno de 0,$65 ; 0,63$ e $0,64 \mathrm{mg} / \mathrm{kg}$ de ração para os períodos de 21 a 35, 36 a 48 e 21 a 48 dias, respectivamente, estão aquém dos recomendados ( 1 a $2 \mathrm{mg} / \mathrm{kg}$ de ração) por empresas comerciais especializadas (Roche, sem data; DSM, 2005), que se baseiam no conceito do nível de fortificação de vitaminas, que resulta no retorno econômico do investimento. No entanto, estão acima dos valores 0,30 e $0,40 \mathrm{mg} / \mathrm{kg}$ de ração recomendados pelo NRC (1998) e por Rostagno et al. (2000), respectivamente. São superiores ainda aos utilizados por empresas brasileiras, como as investigadas por Benati (1996), que, a partir de levantamento realizado com dez empresas, encontrou valor médio de $0,60 \mathrm{mg} / \mathrm{kg}$ de ração de folacina para rações pré-iniciais e constatou que nove entre dez empresas usam, em média, $0,47 \mathrm{mg} / \mathrm{kg}$ de ração. Também diferiram dos valores utilizados por nutricionistas brasileiros de empresas de integração e independentes, que são de 0,30 a $0,42 \mathrm{mg} / \mathrm{kg}$ de ração para rações pré-iniciais, segundo levantamento realizado por Pupa et al. (2005). Esse fato evidencia que rações suplementadas com acidificantes à base de ácido fórmico podem demandar níveis mais elevados de ácido fólico, em virtude de um possível aumento em sua demanda pelo organismo.

A absorção e o transporte do ácido fólico podem ser influenciados por alterações do $\mathrm{pH}$ intraluminal (McDowell, 2000), que, segundo Selhub \& Rosenburg (1996), é absorvido por difusão quando o pH intestinal está próximo de 6,0 . Pode-se, portanto, inferir que o acidificante presente nas dietas experimentais reduz o $\mathrm{pH}$, aumentando a necessidade de ácido fólico quando se utiliza este tipo de aditivo em dietas para leitões recém-desmamados.

Os resultados do hemograma são descritos na Tabela 4. Os valores de hematócrito, hemoglobina, hemácias, VCM, HCM, CHCM e leucócitos apresentaram-se dentro da variação normal para a espécie e idade (34 a 43\%; 9 a 13 g\%; 5 a 
Tabela 3 - Peso corporal, CMDR, GPMD e CA de leitões dos 21 aos 48 dias de idade, de acordo com níveis de ácido fólico nas dietas

Table 3 - Body weight, average daily feed intake (ADFI), average daily weight gain ( $A D W G)$, feed:gain ratio ( $F / G)$ of piglets from 21 to 48 days old according to the dietary leves of folic acid

Nível de ácido fólico ( $\mathrm{mg} / \mathrm{kg}$ de ração) $\quad \mathrm{CV}(\%)$ Level of folic acid $(\mathrm{mg} / \mathrm{kg}$ of diet)

\begin{tabular}{llllll}
\cline { 2 - 4 } $\begin{array}{l}\text { Variável } \\
\text { Variable }\end{array}$ & 0,0 & 0,30 & 0,60 & 0,90 & 1,20 \\
\hline
\end{tabular}

Peso corporal $(\mathrm{kg})$

Body weight

$\begin{array}{lrrrrrr}\text { Inicial } & 5,65 & 5,66 & 5,67 & 5,68 & 5,67 & 1,9 \\ \begin{array}{l}\text { Initial } \\ \text { Final }\end{array} & 14,11 & 14,27 & 15,14 & 14,85 & 14,15 & 10,7\end{array}$

CMDR (g/dia)

ADFI (g/day)

$\begin{array}{llllllll}21 \text { a } 35 & 273,2 & 272,8 & 301,9 & 293,9 & 288,9 & 12,8 \\ 36 \text { a } 48 & 608,0 & 627,1 & 655,4 & 649,4 & 628,0 & 7,52 \\ 21 \text { a } 48 & 434,4 & 443,4 & 472,1 & 465,1 & 452,2 & 7,38\end{array}$

GPMD (g/dia)

$A D W G($ g/day $)$

\begin{tabular}{|c|c|c|c|c|c|c|}
\hline a & 202,5 & 211,8 & 246,6 & 226,9 & 208,8 & 13,6 \\
\hline 4 & & & & 60,8 & 427,3 & 8,59 \\
\hline a $48 * 3$ & 3133 & 318,8 & 350,9 & 339.5 & 314,0 & \\
\hline
\end{tabular}

CA $(\mathrm{g} / \mathrm{g})$

$F / G(g / g)$

\begin{tabular}{lllllll}
21 a $35^{* 4}$ & 1,35 & 1,29 & 1,22 & 1,30 & 1,38 & 6,34 \\
36 a 48 & 1,41 & 1,45 & 1,43 & 1,41 & 1,47 & 8,62 \\
21 a 48 & 1,39 & 1,39 & 1,35 & 1,37 & 1,44 & 6,15 \\
\hline
\end{tabular}

* Efeito quadrático $(\mathrm{P}<0,05)$ (Quadratic effect).

$1 \hat{Y}=0,198201+0,113198 X-0,086670 X^{2} ; R^{2}=0,74$

$2 Y=0,425822+0,102136 X-0,080586 X^{2} ; R^{2}=0,66$

$3 \hat{Y}=0,307796+0,107872 X-0,083741 X^{2} ; R^{2}=0,73$

$4 \mathrm{Y}=1,35804-0,381617 \mathrm{X}+0,335784 \mathrm{X}^{2} ; \mathrm{R}^{2}=0,92$

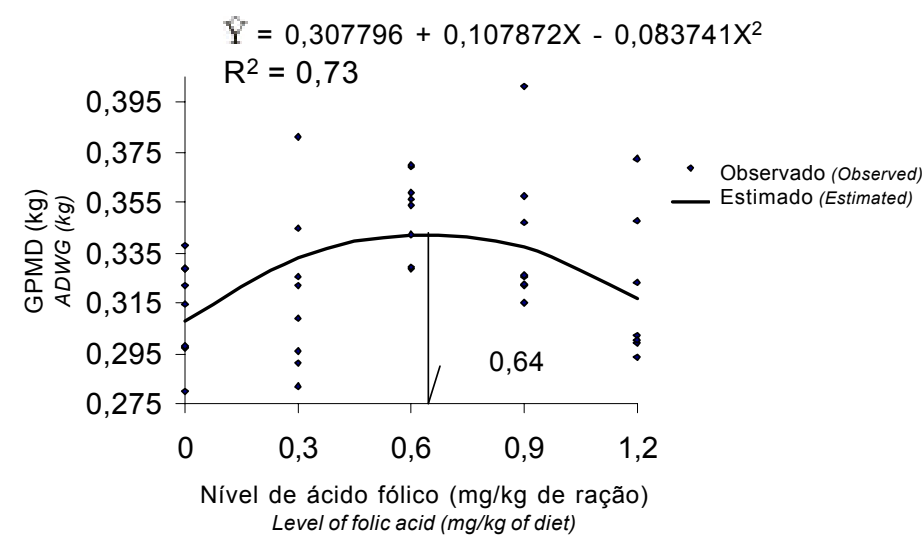

Figura 1 - Efeitos dos níveis de ácido fólico das dietas com ácido fórmico sobre o GPMD de leitões de 21 a 48 dias de idade.

Figure 1 - Average daily weight gain (ADWG) according to the dietary levels of folic acid with formic acid for piglets from 21 at 48 days old.
7 milhões/mm; 44 a $66 \mu$ 3; 15,2 a $24 \mu \mu \mathrm{g} ; 29$ a 34,7\% e 11 a $22 \mathrm{~mm} / 3$, respectivamente), de acordo com amplitudes sugeridas por Duncan \& Prasse (1986), Tumbleson et al. (1986), Jain (1993), Garcia-Navarro \& Pachaly (1998) e Pardini (2003b), não caracterizando a presença de anomalias como anemia.

Os tratamentos aumentaram de forma linear $(\mathrm{P}<0,05)$ os valores de hematócrito, hemoglobina e hemácias. Esta resposta à suplementação com ácido fólico torna-se importante, visto que número inadequado, anemia ou funcionamento deficiente de eritrócitos impede o suprimento suficiente de oxigênio nos tecidos (Swenson, 1996), o que poderia limitar a capacidade de degradação do formiato e uma possível toxemia.

O baixo aporte de ácido fólico pode resultar em anemia megaloblástica (McDowell, 2000), caracterizada pelo aumento de todas as células de proliferação rápida do corpo, em que a maior anormalidade é a capacidade reduzida de síntese de ácido desoxirribonucléico (DNA), com células apresentando uma fase intermitótica de repouso prolongada como um bloqueio precoce na mitose. A síntese de ácido ribonucléico (RNA) é menos prejudicada que a de DNA. Conseqüentemente, a maturação e o crescimento citoplasmático continuam aumentando o número das células (Henry, 1999). Por sua vez, o ácido fólico, assim como a vitamina $\mathrm{B}_{12}$, é necessário para a síntese de DNA em todas células do corpo, incluindo os eritrócitos, e funciona em diferentes vias metabólicas, sendo necessário também para a síntese de RNA nos eritrócitos. Ambas as vitaminas agem como coenzimas na síntese de ácidos nucléicos ou seus constituintes, como bases purínicas e pirimidínicas (Swenson, 1996).

Segundo Garcia-Navarro \& Pachaly (1998), a carência de ácido fólico ou de vitamina B12 determina anemia megaloblástica - o número de divisões dos precursores nucleados dos eritrócitos é diminuído e, por isso, essas células aparecem em número menor e maior tamanho, daí o nome de megaloblastos. A anemia é, geralmente, diagnosticada em laboratório por níveis baixos de hematócrito, hemoglobina e eritrócitos, com VCM e CHCM normais no caso de anemias não regenerativas.

Os resultados deste trabalho diferem dos obtidos em outras pesquisas nas quais se avaliou a influência do ácido fólico isoladamente, como relatado por Gannon \& Leibholz (1991), que avaliaram diferentes níveis de ácido fólico (0 a $2,0 \mathrm{mg} / \mathrm{kg}$ ) suplementados em dietas para suínos em crescimento e não observaram diferenças nos valores de hematócrito e hemoglobina. Também Polonen et al. (1997) administraram ácido fólico para visões (Mustela vision) e 
não observaram diferença nos valores hematológicos ou ocorrência de anemia megaloblástica, trombopenia e leucopenia, típicas da deficiência de folato. A administração de ácido fólico também aumentou os níveis de hemoglobina em bezerros (Lévesque et al., 1993)

De forma similar, em recente estudo em humanos, Chiplonkar et al. (2003) evidenciaram relação entre o baixo consumo de ácido fólico e a incidência de anemia. Baixa correlação positiva foi obtida entre consumo de ácido fólico e hemoglobina, porém dados da mesma pesquisa apontaram valores de hematócrito, MCV e MCH significativamente menores em grupos com anemia moderada em comparação aos do grupo controle.

Neste estudo, não houve efeito $(\mathrm{P}>005)$ dos tratamentos sobre as variáveis VCM, HCM e CHCM. Os leucócitos apresentaram valores numéricos tendendo a efeito linear, mas não-significativo. A diminuição dos valores de

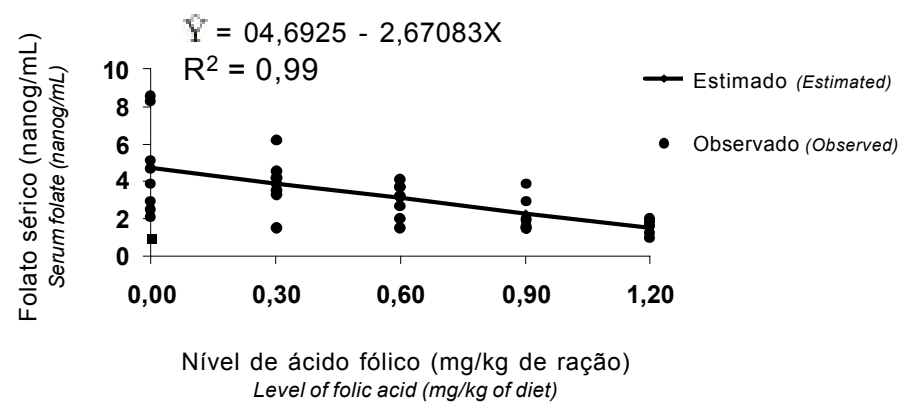

Figura 2 - Efeito dos níveis de ácido fólico na dieta com ácido fórmico sobre a concentração de folato sérico em leitões aos 49 dias de idade.

Figure 2 - Concentration of serum folate according to the dietary levels of folic acid with formic acid for piglets at 49 days old. leucócitos (leucopenia) ocorre em razão da deficiência de ácido fólico, endotoxinas bacterianas ou toxemia (Swenson, 1996; McDowell, 2000). Entretanto, valores altos podem ser indicativos de infecções (Imlah \& Mctaggert, 1977).

Ambrosi et al. (1999) avaliaram o efeito isolado de ácido fólico e não observaram influência na contagem de células brancas e vermelhas, VCM e plaquetas após suplementação por um período de quatro meses em suínos em crescimento e terminação. Conforme Swenson (1996), valores elevados de VCM indicam anemia macrocítica e leucopenia.

A concentração de folato sérico nos leitões alimentados com acidificante à base de ácido fórmico apresentou efeito linear decrescente $(\mathrm{P}<0,01)$ com o aumento de ácido fólico na dieta (Figura 2).

Diferentemente dos resultados apresentados neste trabalho, pesquisas têm apontado aumento no conteúdo de folato no sangue com a suplementação de ácido fólico em dietas para fêmeas suínas em gestação e/ou lactação (Matte \& Girard, 1989; Matte et al., 1993; Harper et al., 1994; Guay et al., 2002). Polonen et al. (1997) verificaram aumento nas concentrações de folato no plasma e no fígado de visões (Mustela vision) recebendo ácido fólico na dieta. Matte et al. (1993), por sua vez, concluíram que a adição de níveis elevados (15 mg/kg de ração) de ácido fólico não foi suficiente para manter constante o status de folato quando houve aumento da demanda na primeira metade da gestação de matrizes suínas.

O contraste entre os resultados deste trabalho e os apresentados na literatura podem ser decorrentes da nãoespecificação da forma de folato determinada na avaliação laboratorial, dificultando a comparação com formas definidas

Tabela 4 - Parâmetros hematológicos de leitões aos 49 dias de idade, segundo os níveis de ácido fólico em dietas com ácido fórmico Table 4 - Hematological parameters of piglets at 49 days old in function of levels of folic acid in diets with formic acid

\begin{tabular}{|c|c|c|c|c|c|c|}
\hline \multirow[b]{2}{*}{$\begin{array}{l}\text { Hemograma } \\
\text { Hemogram }\end{array}$} & \multicolumn{5}{|c|}{$\begin{array}{l}\text { Nível de ácido fólico }(\mathrm{mg} / \mathrm{kg} \text { ração) } \\
\text { Level of folic acid ( } \mathrm{mg} / \mathrm{kg} \text { diet })\end{array}$} & \multirow[t]{2}{*}{ CV (\%) } \\
\hline & 0,0 & 0,30 & 0,60 & 0,90 & 1,20 & \\
\hline $\begin{array}{l}\text { Hematócrito* (\%) } \\
\text { Hematocrit }\end{array}$ & 34,6000 & 34,9500 & 35,0425 & 36,1000 & 41,0750 & 8,17 \\
\hline $\begin{array}{l}\text { Hemoglobina* (g \%) } \\
\text { Hemoglobin }\end{array}$ & 10,8650 & 10,7850 & 10,7850 & 11,3125 & 12,7500 & 8,90 \\
\hline $\begin{array}{l}\left.\text { Hemácias* (milhões } / \mathrm{mm}^{3}\right) \\
\text { Red cell }\end{array}$ & 5,8700 & 5,9575 & 6,0750 & 6,3275 & 6,9375 & 8,08 \\
\hline $\begin{array}{l}\mathrm{VCM}\left(\mathrm{m}^{3}\right) \\
M C V\end{array}$ & 59,0027 & 58,6636 & 57,6512 & 58,2292 & 59,4406 & 5,73 \\
\hline $\begin{array}{l}\mathrm{HCM}(\mathrm{mmg}) \\
M C H\end{array}$ & 18,2263 & 17,8018 & 17,9233 & 18,2908 & 18,4364 & 4,57 \\
\hline $\begin{array}{l}\mathrm{CHCM} \quad(\%) \\
M C H C\end{array}$ & 31,4064 & 30,7935 & 30,7967 & 31,3332 & 31,0257 & 2,25 \\
\hline $\begin{array}{l}\text { Leucócitos }(\mathrm{mm} / 3) \\
\text { Leukocytes }\end{array}$ & 17,4250 & 17,5625 & 18,3750 & 18,9150 & 20,8000 & 36,4 \\
\hline
\end{tabular}

\footnotetext{
${ }^{*}$ Efeito linear (Linear effect), $\mathrm{P}<0,05$.
} 
em estudos anteriores. Para maior acurácia na obtenção do status de folato e de suas unidades metabólicas de interconversão, são necessárias mais investigações acerca dos métodos de análise de detecção de folato sangüíneo para suínos, como sugerido por Mizuno et al. (2000). Harper et al. (2003) observaram aumento na concentração de formas distintas de folato no sangue, ao compararem formas reduzidas e oxidadas de suplementação de ácido fólico para fêmeas suínas. No entanto, não apresentaram efeito sobre os parâmetros reprodutivos, sugerindo não haver correlação entre o status fólico e os índices de produção. Neste caso, a suplementação de fontes reduzidas de ácido fólico aumentou a concentração plasmática de folatos mais efetivamente que as fontes oxidadas.

Matte \& Girard (1999) também registraram diminuição da concentração de folatos após suplementação única e em função do aumento da suplementação de ácido fólico na dieta. Segundo esses autores, esse efeito é possível a partir da alteração na absorção das diferentes formas de ácido fólico no intestino quando níveis altos de ácido fólico são acrescidos à dieta. $\mathrm{O}$ ácido fólico disponível para absorção no intestino é uma combinação de fonte dietética (ácido fólico principalmente sintético) e folatos biliares (formas biológicas reduzidas, Kokue et al., 1998) do ciclo enterohepático, importante fonte para a manutenção do status de folato (Steinberg et al., 1982). Porém, a partir de determinado nível, o ácido fólico sintético se torna um competidor com os folatos biliares por absorção no intestino (Selhub et al., 1984; Kudo et al., 1995). Então, é possível que, com o aumento da suplementação dietética de ácido fólico, uma parte importante de folatos biliares seja excretada nas fezes em vez de ser reabsorvida pelo intestino. Parte do ácido fólico sintético absorvido é reduzida dentro da parede intestinal (Arranhe, 1979), mas a maior parte é dirigida para o fígado. Em suínos, a habilidade do fígado em transformar o ácido fólico sintético para seu estado reduzido metabolicamente ativo é limitada, em comparação a outros animais, como ratos (Kokue et al., 1998).

Segundo Mizuno et al. (1997), a suplementação de ácido fólico sintético na forma oxidada não aumenta os níveis de folato do plasma após administração oral única e a longo prazo. Esses pesquisadores sugeriram três hipóteses para esse evento e que podem também justificar a tendência de diminuição do folato sérico neste experimento: 1) inibição competitiva na absorção intestinal do ácido fólico com folatos endógenos derivados da circulação enterohepática, visto que grandes quantidades de folatos endógenos são recicladas por esta circulação (Steinberg, 1984; Shin et al., 1995) e absorvidas ativamente na mucosa intestinal; 2) competição de ligação do ácido fólico sobre o tetrahidrofolato para a proteína de ligação de folato no plasma (o ácido fólico entrando no sistema circulatório pode libertar tetrahidrofolato do sítio de ligação de proteína de ligação de folatos, expondo o tetrahidrofolato à possível degradação na circulação e/ou melhorando a eficiência renal de liberação de tetrahidrofolato); e 3 ) reduzida conversão de ácido fólico para folato reduzido, ou seja, baixa atividade de folato redutas no fígado de suínos, uma vez que administração de dihidrifolato aumenta os níveis de folatos no plasma, o que não ocorre com o ácido fólico (Mizuno et al., 1997). Essas hipóteses também podem ser apontadas para justificar a ausência de correlação entre os valores de folato sérico e o aumento de suplementação de ácido fólico neste experimento, uma vez que a metodologia empregada quantifica folatos totais e não especifica as formas oxidadas e reduzidas. Da mesma forma que, com a não-definição das formas específicas de folatos séricos, torna-se difícil a correlação entre a resposta de desempenho e a resposta de dosagem sérica de folato, necessitando de novos estudos e maiores evidências científicas.

\section{Conclusões}

Os dados de desempenho, nas condições em que foi realizado o experimento, demonstram que dietas para leitões de 21 a 48 dias de idade suplementadas com acidificante à base de ácido fórmico demandam suplementação de ácido fólico na proporção de aproximadamente de $0,64 \mathrm{mg} / \mathrm{kg} \mathrm{de}$ ração. O aumento da suplementação de ácido fólico aumenta de forma linear as concentrações de hematócrito, hemoglobina e hemácias.

\section{Literatura Citada}

AMBROSI, P.; ROLLAND, P.H.; BODARD, H. et al. Effects of folate supplementation in hyperhomocysteinemic pigs. Journal of the American College of Cardiology, v.34, n.1, 1999.

BENATTI, M. Níveis nutricionais utilizados nas dietas de suínos. In: SIMPÓSIO INTERNACIONAL SOBRE EXIGÊNCIAS NUTRICIONAIS DE AVES E SUÍNOS, 1996, Viçosa, MG. Anais...Viçosa, MG: Universidade Federal de Viçosa, 1996. p. $445-457$

BUCKLEY, W.T. Trace element dynamics. In: MELLO, I.D., FELIX, J.P. (Eds.) Farm animal metabolism and nutrition. Wallingford: CAB International, 2000. p.161-182.

CANIBE,N.; STEIEN, S.H.; ØVERLAND, M. et al. Effect of K-diformate in starter diets on acidity, microbiota, and the amount of organic acids in the digestive tract of piglets, and on gastric alterations. Journal of Animal Science, v.79, p.2123-2133, 2001.

CHIPLONKAR, S.A.; AGTE, V.V.; MENGALE, S.S. Relative importance of micronutrient deficiencies in iron deficiency anemia. Nutrition Research, v.23, p.1355-1367, 2003. 
DOVE, C.R.; COOK, D.A. Water-soluble vitamins in swine nutrition. In: LEWIS, A.J.; SOUTHERN, L.L. (Eds.) Swine nutrition. 2.ed. Washington: CRC Press, 2001. p.315-356.

DSM. Swine fortification guidelines. Disponível em: http:// www.dsm.com/en US/html/dnpus/an fort guide swine.htm. Acessado em: 20/07/2005.

DUNCAN, J.R.; PRASSE, K.W. Veterinary laboratory medicine. 2.ed. Iowa: Iowa State University Press, 1986. p.285.

EASTER, R.A.; ANDERSON, P.A.; MICHEL, E.J. et al. Response of gestating gilts and starter, grower and finisher swine to biotin, pyridoxine, folacin and thiamine additions to cornsoybean meal diets. Nutrition Reports International, v.28, p.945, 1983

ECKEL, B.; KIRCHGEBNER, M.; ROTH, F.X. Influence of formicacid on daily weight-gain, feed-intake, feed conversion rate and digestibility .1. Communication investigations about the nutritive efficacy of organic-acids in the rearing of piglets. Journal of Animal Physiology and Animal Nutrition, v.67, p.93-100, 1992.

EIDELSBURGER, U.; KIRCHGEßNER, M.; ROTH, F.X. Influence of fumaric-acid, hydrochloric-acid, sodium formate, tylosin and toyocerin on daily weight-gain, feed-intake, feed conversion rate and digestibility. 11 . Investigations about the nutritive efficacy of organic-acids in the rearing of piglets. Journal of Animal Physiology and Animal Nutrition, v.68, p.82-92, 1992.

EWAN, R.C. Vitaminas. In: SWENSON, M.J.; REECE, W.O. (Eds.) Dukes - fisiologia dos animais domésticos. 11.ed. Rio de Janeiro: Guanabara Koogan, 1996. p.456-469.

GARCIA-NAVARRO, C.E.K.; PACHALY, J.R. Manual de hematologia veterinária. 1.ed. $1^{\text {a }}$ Reimpressão. São Paulo: Varela, 1998. p.169.

GANNON, N.J.; LEIBHOLZ, J. The effect of folic acid supplementation on the haematological status of growing pigs. Pig News and Information, v.12, n.3, p.484, 1991.

GIESTING, D.W.; EASTER, R.A. Effect of protein source and fumaric acid supplementation on apparent ileal digestibility of nutrients by young pigs. Journal of Animal Science, v.69, p.2497-2503, 1991

GUAY, F.; MATTE, J. J.; GIRARD, C.L. et al. Effect of folic acid and glycine supplementation on embryo development and folate metabolism during early pregnancy in pigs. Journal of Animal Science, v.80, p.2134-2143, 2002.

GRASSMANN, E.; ROTH, F.X.; KIRCHGESSNER, M. Metabolic effects by dietary use of formic acid. 6. Investigations about nutritive efficacy of organic acids in the rearing of piglets. Journal of Animal Physiology and Animal Nutrition, v.67, n.5, p.250, 1992 .

HARPER, A.F.; KNIGHT, J.W.; KOKUE, E. et al. Plasma reduced folates, reproductive performance, and conceptus development in sows in response to supplementation with oxidized and reduced sources of folic acid. Journal of Animal Science, v.81, p.735-744, 2003

HARPER, A.F.; LINDEMANN, M.D.; CHIBA, L.I. et al. An assessment of dietary folic acid levels during gestation and lactation on reproductive and lactational performance of sows: a cooperative study. Journal of Animal Science, v.72, p.2338-2344, 1994.

HENRY, J.B. Diagnósticos clínicos e tratamento por métodos laboratoriais. 19.ed. São Paulo: Manole, 2000. 1550p.

IMLAH, P.; MCTAGGERT, H.S. Heamatology of the pig. In: ARCHER, R.K.; JEFFCOTT, L.B. (Eds.). Comparative clinical haematology. Oxford: Blackwell Scientific Publishers, 1977. p.271-303.

JAIN, N.C. Essentials of veterinary hematology. Philadelphia: Lea \& Febiger, 1993. 417p.

JOHLIN, F.C.; FORTMAN, C.S.; NGHIEM, D.D. et al. Studies on the role of folic acid and folate-dependant enzymes in human methanol poisoning. Molecular Pharmacology, v.31, p. $557-561,1987$.
KIRCHGEßNER, M.; ROTH, F.X. Use of formats in the feeding of piglets. 1. Calcium formate. Landwirtsch Forsch, v.40, p.141$152,1987 \mathrm{a}$.

KIRCHGEßNER, M.; ROTH, F.X. Use of formats in piglet nutrition. 2. Sodium formate. Landwirtsch Forsch, v.40, p.287-294, 1987b.

KIRCHGEßNER, M.; \& ROTH, F.X. Nutritive effect of calcium formate in combination with free acids in the feeding of piglets. Agrobiological Research, v.43, p.53-64, 1990.

LÉVESQUE, J.; GIRARD, C.L.; MATTE, J.J. et al. Dietary supplements of folic acid: blood and growth responses of white veal calves. Livestock Production Science, v.34, p.71-82, 1993.

LETENDRE, M.; GIRARD, C.L.; MATTE, J.J. et al. Effect of intramuscular injections of folic acid on folates status and growth performance of weanling pigs. Canadian Journal of Animal Science, v.71, p.1223-1231, 1991.

LIMA, G.J.M.M. Uso de aditivos na alimentação de suínos. In: SIMPÓSIO SOBRE AS IMPLICAÇÕES DO USO DE ADITIVOS NA PRODUÇÃO ANIMAL, 1999, Piracicaba. Anais... Piracicaba: 1999. p.51-68.

LINDEMANN, M.D.; BLODGETT, D.J.; KORNEGAY, E.T. et al. Potential ameliorators of aflatoxicosis in weanling/growing swine. Journal of Animal Science, v.71, p.171, 1993.

LINDEMANN, M.D.; KORNEGAY, E.T. Folic acid additions to weanling pig diets. Journal of Animal Science, v.63 (Supl. 1): p.35 (Absctract), 1986.

MAKAR, A.B.; TEPHLY, T.R.; SAHIN,G. et al. Formate metabolism in young swine. Toxicology and Applied Pharmacology. v.105, p.315-320, 1990.

MATTE, J.J.; GIRARD, C.L. Effects of intramuscular injections of folic acid during lactation on folates in serum and milk and performance of sows and piglets. Journal of Animal Science, v.67, p.426-431, 1989.

MATTE, J.J.; GIRARD, C.L.; TREMBLAY, G.F. Effect of longterm addition of folic acid on folate status, growth performance, puberty attainment, and reproductive capacity of gilts. Journal of Animal Science, v.71, p.151-157, 1993.

McDOWELL, L.R. Vitamins in animal nutrition. San Diego: Academic Press, 1989. 486p.

McDOWELL, L.R.Vitamins in animal and human nutrition. Iowa: Iowa State University Press, 2000. 793p.

MIZUNO, Y.; KOKUE, E.; OHNISHI, N. et al. Effect of oral administration of folate sources on plasma folate levels in pigs: Comparison between reduced and oxidized forms of folate. Canadian Journal of Animal Science, v.77, p.497-502, 1997.

MIZUNO, Y.; NASUNO, T.; OKUSA, S. et al. 10Formyltetrahydrofolate exists in pig plasma. Nutrition Research, v.20, n.9, p.1355-1359, 2000.

MROZ, Z. Acidifiers, phytases and their interactions in feeding of pigs and poultry. In: TECHNICAL MEETING ON ADDITIVES AND NEW FEED TECHNOLOGIES, EFFECTS OF THEIR INTERATIONS AND SPECIFICATIONS OF USE. Madrid, Espana, 2002, Madrid. Proceedings... Madrid: 2002. 51p.

NATIONAL RESEARCH COUNCIL - NRC. Nutrient requirement of swine. 10.ed. Washington, D.C.: National Academy of Sciences, 1998. 189p.

PARDINI, H. Manual de coleta e exames veterinários. Belo Horizonte: H. Pardini, Instituto de Patologia Clínica. Divisão Veterinária, 2003a. 56p.

PARDINI, H. Guias de referências para exames veterinários. Belo Horizonte: H. Pardini, Instituto de Patologia Clínica. Divisão Veterinária, 2003b. 1825 p.

PARTANEN, K. Organic acids - their efficacy and modes of action in pigs. In: PIVA, A.; BACH KNUDSEN, K.E.; LINDBERG, J.E. (Eds.). Gut environment of pigs. Nottigham: Nottigham University Press, 2001. p.201-217.

PAULICKS, B.R.; ROTH, F.X.; KIRCHGEßNER, M. Dose effects of potassium diformate (Formi(TM) LHS) on the performance of growing piglets. Agribiological Research, v.49, n.4, p.318-326, 1996. 
PAULICKS, B.R.; ROTH, F.X.; KIRCHGESSNERJ, M. Effects of potassium diformate (Formi 1 LHS) in combination with different grains and energy densities in the feed on growth performance of weaned piglets. Journal of Animal Physiology and Animal Nutrition, v. 84, p.102-111, 2000

POLÖNEN, I.; VAHTERISTO, L.T.; TANHUANPÄÄ, E.J. Effect of Folic Acid Supplementation on Folate Status and Formate Oxidation Rate in Mink (Mustela vision). Journal of Animal Science, v.75, p.1569-1574, 1997.

POLÖNEN, I.; VALAJA, J.; JALAVA, T. et al. Effect of hepatic folic acid status on formic acid metabolism in blue foxes (Alopex lagopus). Animal Feed Science and Technology, v.99, p.189-194, 2002.

PUPA, J.M.R.; ORLANDO, U.A.D.; HANNAS, M.I. et al. Níveis nutricionais utilizados nas dietas de suínos no Brasil. In: SIMPÓSIO INTERNACIONAL SOBRE EXIGÊNCIAS NUTRICIONAIS DE AVES E SUÍNOS, 2., 2005, Viçosa, MG. Anais... Viçosa, MG, 2005. p.349-374.

ROCHE VITAMIN NUTRITION COMPENDIUM. CD-ROM. Sem data conhecida.

ROSTAGNO, H.S.; ALBINO, L.F.T.; DONZELE, J.L. et al Composição de alimentos e exigências nutricionais de aves e suínos: tabelas brasileiras. Viçosa, MG: Universidade Federal de Viçosa, 2000. 141p.

SELHUB, J.; ROSENBERG, I.H. Folic acid. In: ZIEGLER, E.E.; FILER, L.J. (Eds.) Present knowledge of nutrition. 7.ed. Washington, D.C.: International Life Sciences Institute, 1996. p.206-219.

SHIN, H-C.; SHIMODA, M.; KOKUE, E. Enterohepatic circulation konetics of bile-active folate derivatives and folate homeostasis. American Journal Physiology, v.269, p.R421-R425, 1995. STEINBERG, S.E. Mechanisms of folate homeostasis. American Journal Physiology, v.246, p.G319-G324. 1984.
SWENSON, M.J. Propriedades fisiológicas e componentes químicos e celulares do sangue. In: SWENSON, M.J.; REECE, W.O. (Eds.) Dukes fisiologia dos animais domésticos. 11.ed. Rio de Janeiro: Guanabara Koogan, 1996. p.19-43.

TEIXEIRA, M.P.; SILVA, G.F.; LOPES, D.C. et al. Avaliação de ácidos orgânicos e inorgânicos em dietas para leitões desmamados aos 21 dias de idade. In: REUNIÃO ANUAL DA SOCIEDADE BRASILEIRA DE ZOOTECNIA, 40., 2003, Santa Maria, Anais... Santa Maria: Sociedade Brasileira de Zootecnia, 2003. CD-ROM.

TEPLY, T.R. The toxicity of methanol. Life Sciences, v.48, p.1031-1041, 1991

TREMBLAY, G.F.; MATTE, J.J.; LEMIEUX, L. et al. Serum folates in gestating swine after folic acid addition to diet. Journal of Animal Science, v.63, p.1173-1178, 1986.

TSILOYIANNIS, V.K.; KYRIAKIS, S.C.; VLEMMAS, J. et al. The effect of organic acids on the control of porcine post-weaning diarrhea. Research in Veterinary Science, v.70, p.287-293, 2001.

TUMBLESON, M.E.; SCHMIDT, D.A.; SCHOLL, E. Hematology and clinical chemistry. In: LEMAN, A.D. (Ed.) Diseases of swine. 6.ed. Iowa: Iowa State University Press, 1986. p.27-35.

UNIVERSIDADE FEDERAL DE VIÇOSA - UFV. SAEG - Sistema para Análises Estatísticas e Genética. Versão 8.0. ViçosaMG: 1999. (Manual do usuário).

VERGDUT, B.V. 2002. The Netherlands. Acid binding capacity in feedstuffs. E.mail: sales@verdugt.nl.

Recebido: 21/05/04 Aprovado: 08/11/05 